\title{
Opening up and closing down: how teachers and TAs manage turn-taking, topic and repair in mathematics lessons
}

\author{
Julie Radford, Peter Blatchford and Rob Webster
}

Institute of Education, Psychology and Human Development, 25 Woburn Square, London WC1H OAA

\section{Learning and Instruction (accepted Jan 2011)}

\begin{abstract}
Support for children with special educational needs in inclusive classrooms is increasingly provided by teaching assistants (TAs). They often have a direct pedagogical role, taking responsibility for instruction in mathematics. The quality of TAs' oral skills is crucial for learning but has rarely been researched. Using conversation analysis, this study compares teacher and TA talk in terms of turn allocation, topic generation and repair. From 130 recordings, transcripts of mathematics teaching in four lessons were analysed in depth. We found that teachers open up students whilst TAs close down the talk. Teachers, with whole classes, adopt inclusive teaching strategies to ensure oral participation whereas TAs, working with individuals, emphasise task completion. Teachers use open strategies for topic generation whilst TAs ask closed questions. Teachers withhold correction with prompts and hints while TAs supply answers. The findings are interpreted with reference to the TA role and implications for management and training.
\end{abstract}

\section{Key words}

classroom discourse; mathematics; conversation analysis; instruction; teaching assistants 


\section{INTRODUCTION}

In recent years there has been a huge increase in the number of paraprofessionals working in schools. For example, from 1997 to 2010, the number of full time equivalent support staff in English schools rose from 133,500 to 362,600 (DFE ${ }^{1}$ ). This increase is paralleled in other countries such as Finland, Germany and the United States (Giangreco \& Doyle, 2007; Giangreco et al., 2010). The names used for para-professionals who provide support in inclusive classrooms vary across countries: special needs assistant is used in Ireland (Logan, 2006), teacher aide in Australia and the United States (Bourke and Carrington, 2007; Giangreco et al., 2010) and learning support assistant or teaching assistant (TA) or higher level teaching assistant, in England, where TAs now comprise 24\% of the overall school workforce. Developments that have contributed to the growth in support staff in the UK include: the delegation of funding for special educational needs (SEN); the introduction of literacy and numeracy strategies; and the implementation of 'The National Agreement', which aimed to raise pupil standards and tackle teacher workload via new and expanded support roles (DfES, 2003).

Although most studies have been conducted in England and the United States, the actual role of TAs varies both within and across countries, (Giangreco \& Doyle, 2007; Giangreco, 2010). Increasingly, TAs work predominantly with pupils with low ability/ SEN and disability ${ }^{2}$ (Blatchford et al., 2009a). Furthermore, with respect to these learners, TAs spend most of their time in a direct pedagogical role, supporting and interacting with pupils (Blatchford et al., 2009a; Blatchford et al, 2009b) yet this development is controversial.

Findings from a large scale longitudinal study of over 8,000 pupils, known as the DISS project (Deployment and Impact of Support Staff), gives weight to this controversy. It found that the pupils who received most support from TAs made

\footnotetext{
${ }^{1}$ Dept. for Education. 2010. School workforce in England (including pupil: teacher ratios and pupil: adult ratios) January 2010 (provisional), SFR11/2010, London: DCSF.

2 By SEN and disability, we mean pupils with special educational needs who are registered as School Action or School Action Plus as well as those with an SEN statement.
} 
significantly less progress in mathematics, English and science than similar pupils with less TA support, even after controlling for pupil characteristics likely to be the reason for TA support, like prior attainment and level of SEN (Blatchford et al, in pressa). For some age groups and subjects this effect was most marked for pupils with SEN (Blatchford et al, in pressb). The main explanation for these findings appears to be that TA-supported pupils become separated from their teachers and the curriculum as a result of spending more time with TAs. Observational studies conducted as part of the DISS project also showed that the more support pupils received from TAs, the less interaction they had with the teacher. TAs had inadvertently become the primary front-line educators of low attaining pupils and pupils with SEN/disabilities. Contrary to Government policy, TAs therefore offer alternative rather than additional support. This makes it urgent that we have better understanding of the quality of the talk that takes place during interactions between TAs and pupils, a topic that has not been studied to date in any detail.

To address this issue, observation data on pupil-adult dialogue were collected in English and mathematics lessons (Blatchford et al., 2009a). Using a coding frame drawn from Berliner's instructional model (1987) it was found that teachers engaged in significantly more explanations of concepts and feedback whereas TAs used more prompts and questions. Overall, it was concluded that TAs compared to teachers tended to be concerned with task completion, not learning, and tended to be reactive rather than proactive in interactions with pupils (Rubie-Davies et al, in press).

The main purpose of this paper is to explicate more fully ways in which teachers and TAs use language in inclusive classrooms. Whereas the RubieDavies study coded only adult turns, a more fine-grained analysis is now needed in order to illustrate precisely the nature of the instructional strategies and their effects on learner participation. Furthermore, no detailed observational study has yet been conducted that explicates the TAs' involvement in learning episodes. The study therefore makes use of the techniques of conversation analysis (CA) which is proving a highly valuable tool for gaining detailed insights into pedagogical discourse (Gibson, 2009; Koshik, 2002; McHoul, 1978; 1990). CA as a discipline has its origins in 
Garfinkel's ethnomethodology and Goffman's studies of order in interaction. The approach is expressly inductive, as it involves rejecting a priori assumptions about the data and paying open-minded attention to detail (Have, 2007). Using CA thus offers the potential for fresh understanding of how the TA-student and teacher-student interactions compare whilst teaching the same lesson content (mathematical concepts). Instead of coding single utterances, a sequential analysis will take account of the talk of the students as well. This paper will examine selected features of teacher and TA talk with pupils by focusing on three aspects: turn allocation, topic organisation and how repairs are accomplished because, as we shall now discuss, they are central to classroom learning.

First of all, how turn-taking is organised was originally described by Sacks et al. (1974). Applying similar principles to the classroom, in whole class interaction it has been shown that teachers typically allocate turns and students have few opportunities to self-select (Jones and Thornborrow, 2004). In other words, teachers exercise tight control over who has the right to participate. The reason that the system of turn-taking is important for mathematical learning stems from research that aims to characterise which features of effective teacher-pupil dialogue promote conceptual understanding. The notion of 'inclusive teaching' is a key characteristic; it involves creating a classroom culture where each contribution is valued equally and teachers adopting deliberate strategies to ensure that the less able can participate (Black, 2004; Kyriacou and Issitt, 2008). How TAs communicate messages about turn-taking and participation is yet to be explored, bearing in mind that they mainly support individuals and small groups rather than teach whole classes.

Secondly, the way in which topic ${ }^{3}$ is generated also has a significant bearing on the degree of student participation. In a typical classroom, teachers solicit topic through initiations $(I)$ that generate student responses $(R)$ which are subsequently given evaluative feedback (F) (Cazden, 2001). This three part

\footnotetext{
3 'Topic' is used here as a technical term in conversation analysis (Radford and Tarplee, 2000). This is different from how, in mundane talk, we refer to the topic of a conversation.
} 
IRF sequence is widely known and well documented in mathematics lessons (Myhill, 2006; Smith et al., 2004). As teachers have superior epistemic authority, initiations usually involve asking questions to which they already have the answer (Myhill, 2006). Consequently, student answers are brief, despite the promotion of whole class interactive teaching in the National Numeracy and Literacy Strategies in the UK (Smith et al., 2004). One concern is that extensive use of IRF limits student engagement and participation (Hardman et al., 2005). In terms of pedagogy in mathematics, a major research review concludes that 'going beyond IRF' is a likely candidate for effectiveness (Kyriacou and Issitt, 2008). This can be accomplished by initiations such as open questions, devices like 'tell us what you think' and authentic questions to which the adult does not know the answer (Coles, 2002; Myhill, 2006; Smith et al., 2004). Furthermore, when teachers use initiations such as 'open invitations', topic can be jointly constructed, even when a grammatically closed question is asked (Radford et al., 2006). This is because open invitations (e.g. 'Who should be in our story?') solicit students' own ideas and opinions, as opposed to the right answer, and generate student reasoning and explanations. In this way, they satisfy the criteria for dialogic discourse and create valuable learning opportunities (Alexander, 2001; 2008; Fisher, 2007). Going beyond IRF also has implications for feedback moves; it is the key site for displaying genuine interest in student ideas and asking questions to further expand their mathematical thinking (Smith and Higgins, 2006).

As a third area of interest, this paper is concerned with repair sequences. Classroom talk is abundant with errors and misunderstanding because learners, especially those with SEN, are continually pushed to the limits of their understanding. Precisely how adults respond has important implications for student involvement in high quality discourse. CA studies of repair offer a well-established way of showing how adults deal with children's incorrect responses and lack of clarity (Schegloff, 2007; Schegloff et al., 1977). In the classroom, teachers correct children's talk more readily than in everyday conversation (Hauser, 2005; Macbeth, 2006; McHoul, 1990). Yet, to foster student independence, teachers should avoid direct correction and, instead, 
employ strategies such as clueing (McHoul, 1990), prompting, hinting and supplying a model (Radford, 2010a; Radford, 2010b; Ridley, Radford and Mahon, 2002). These studies demonstrate that withholding correction, through use of devices like prompts and hints (also known as otherinitiations), affords students the maximum opportunity to self-repair and find the answer themselves. Indeed, asking for clarification and fostering reasoning through the use of why questions, instead of correction, are listed as candidates for effectiveness in the mathematics classroom (Back, 2005; Kyriacou and Issitt, 2008; Smith and Higgins, 2006).

The key purpose of this paper is to compare TAs and teachers in terms of key dimensions of classroom talk. The comparison is relevant because TAs, like teachers, are often placed in an instructional role in mathematics lessons to support learner(s) with SEN and disabilities. Our questions are: a) How do teachers and TAs allocate turns, initiate topic and deal with repairs when teaching the same lesson content? b) What are the implications of the teacher and TA strategies learning and participation in mathematics lessons?

\section{METHOD}

Data on TA pupil interactions were collected in 2007/8 as part of the DISS study. Audio recordings of adult-pupil interaction were made to provide detailed data on the practices of teachers and TAs. It is results from these recordings that are reported in this paper. Results from other aspects of the DISS study can be found in Blatchford et al. (2009a).

\subsection{Data collection: audio recordings}

In 15 schools (8 primary, 7 secondary), 130 lesson/session length recordings of teacher and support staff talk were made, of which 42 were of the teacher and the TA during the same lessons. Four of these schools were selected for further study. The selection was purposive in so far as there were two primary (year 5) and two secondary classes (year 8) but, otherwise, it was random. The schools were spread geographically and were diverse in terms of their student intake (see Table 1). Lessons were chosen that focused on mathematics rather than literacy. It was not possible, or desirable, to control 
for other variables since the observations were naturalistic and intended to capture everyday instructional practice. The schools and lessons were thus representative of the whole DISS sample. The selection of teacher and TA participants was random and all names are pseudonyms. Information on the lesson focus and the role of the TA is presented in Table 2.

Table 1

Table 2

Digital recordings of each lesson were made and fully transcribed by a transcriber. The analysis entailed repeated examination of the recordings and transcripts by the first author. The initial selection of extracts was motivated by searching for sequences of adult-child talk that had a pedagogical focus. Extracts were chosen that involved talk about the learning of mathematical concepts (as opposed to behaviour management or the organisation of materials) and where both teacher and TA participated in a similar learning experience during the same lesson. As a result, the data for several teachers/ TAs surprisingly produced few relevant instructional episodes, apart from teacher one. The analysis was unmotivated in so far as the discourse patterns and themes emerged from the data. Additional extracts were sought to verify and cross-check emergent ideas. Using constant comparison (Silverman, 2006), the emergent themes were re-worked according to new examples. Line-by-line linguistic analysis was conducted to uncover detail and establish the perspective of the participants (Schegloff, 2007). Questions used to interrogate the data included: 'How is that turn/phrase designed?'; 'Why does $X$ use that turn/phrase now (in relation to the prior turn/s)?'; 'What work does that turn/phrase accomplish (in terms of what happens next)?'

\section{RESULTS}

Several themes emerged from interrogating the data and the analysis is set out in this sequence:

(3.1) turn-taking and opportunities for participation;

(3.2) topic: open approaches vs. closed questions; 
(3.3) repair: as feedback, to foster independence and learning.

Quantitative analysis is not relevant to this research because each learning episode is regarded as unique.

\subsection{Turn-taking and participation}

Listening to the teacher is the single most frequent activity of TAs in primary schools (37\% of the time; contrast $20 \%$ in secondary: Blatchford et al, $2009 \mathrm{~b})$. and $96 \%$ of this time TAs play an active role. What opportunities do they provide for students to participate during whole class listening? In all schools, the TAs listen to the teacher explaining the main purpose and hear about the subject content 'on the spot' with the students.

\subsubsection{Prompting to 'get it right' orally}

TA 1, who sits next to individual students, plays a key role in them getting the right answer (extracts 1-2). In saying 'What do you think', the teacher is using a mental verb which is suited to generating the student's ideas and opinions (compare 3.2.1). As Tom's response is not forthcoming (line 3), the TA uses the $\mathrm{F}$ turn to repeat both the teacher's question as well as the number problem. She prompts, 'Come on' but offers no additional hint or clue to lead Tom to finding the correct answer. It could be interpreted as straightforward encouragement or simply emphasise the need for a right answer.

(1) IRF with prompt and repeat (TA 1)

(10 minutes into lesson in whole class discussion. Tom has support for learning)

1 TA Sit on your chair properly please and listen.

$2 \mathrm{~T}$ What do you think Tom?

3 Tom uhhm uhhm uhhm

$\rightarrow 4$ TA Come on. What do you think? One thousand three hundred

$\rightarrow 5$ and two. Sorry?

6 Tom $\left(^{* \star * *}\right)$

7 TA You need to pay attention darling. 
In (2) the TA is involved in the IRF through repeating and prompting. First, the teacher asks a question and the TA does a verbatim repeat. Sam, hearing both questions, responds correctly at line 3, given the teacher's 'well done'. The TA reminds him of the 'hands up' procedure for giving a class response. She therefore provides useful encouragement for Sam to participate orally in the whole class session.

(2) IRF with repeat and prompt (TA 1)

(17 minutes into lesson in whole class discussion.

Sam has Aspergers)

I $1 T$ What would it be, Sam?

I 2 TA What would it be?

R 3 Sam Twenty

I 4 TA Say it. Put your hand up then.

R 5 Sam Twenty

F 6 T Well done

On a positive note, the TA plays an important role in terms of increasing student participation in whole class discussion; Tom was told the question again which served to re-focus his attention and remind him of the number problem. Furthermore, the encouragement provided by the TA is valuable for potentially improving the motivation and confidence of vulnerable children, especially those who lack verbal confidence.

\subsubsection{Increasing participation by giving all students a voice}

Extract 3 shows the teacher's oral skill in eliciting a variety of the students' ideas following group discussion. Whilst TAs do not in our data play a role in gaining feedback from whole classes, they might have such opportunities when working with small groups. These verbal strategies could therefore be adapted for use by the TA in a group context. The students have been discussing the concept of a 'whole number' and the teacher is pleased with 
their 'good/fantastic teamwork'. She gives them a clear message that working together and collaborating is expected. There is an established turn-taking system for gaining feedback from each discussion group, first, by inviting ideas with an 'open invitation' (4). Use of 'might' suggests that several possible answers are possible, as opposed to a single correct answer. Indeed, she does accept ideas from each group enthusiastically, praising their 'good idea(s)' (lines 6, 10) even when the initial ideas display inaccurate or partial grasp of concept $(5,8,11,12)$. Using 'idea' leaves the floor open for other suggestions, rather than closing down on the right answer. The teacher finally targets the correct answer at 16 and pushes for elaboration (20). She provides particular encouragement when the correct answer (24) is given. Her final turns (24-26) offer very clear explanation of the concept, based on Ruri's answer.

(3) Giving all students a voice (Teacher 1)

(6 minutes into whole class discussion.

Students have no identified disabilities.)

$1 \mathrm{~T}$ I'm really excited because you've had good teamwork. You've used

2 your skills, your numeracy skills and your teamwork was fantastic.

3 So l'm going to come back to this table. I'll start off with this table.

$4 \quad$ What do you think a whole number might be?

5 St It might be something that hasn't got any left, hasn't got like halves in it.

$6 \mathrm{~T}$ It hasn't got any halves in it. Ok, that's a good idea. What about Ross's

$7 \quad$ group? What do you think?

8 St We think it might be a fraction that goes into (.)

$9 \mathrm{~T}$ So you think it's a number that can be multiplied by itself? Fantastic.

10 Ok Amy, you had a good idea.

11 St We thought that one two three (.) that could (.)

12 St If it had a zero at the end, so like a thousand

$13 \mathrm{~T}$ Aah fantastic (.) Oh I see you're thinking whole number without the $\mathrm{W}$, so

14 that sort of hole. So you think it's a number that looks like it might have a

15 hole in it, like a zero, like an eight, like a six. Yes? Very interesting. Well 
16 Ruka was the first person who got it right. So you can tell me what you

17 think it might be.

18 St It hasn't got a half in it.

$19 \mathrm{~T}$ It hasn't got a half in it. And you did say that, this table.

20 But is it just a half?

21 St No

\section{$22 \mathrm{~T}$ What else could it be Ruri?}

23 St A fraction.

$24 \mathrm{~T}$ Any sort of fraction. Well done. Apart from six sixths would mean that it is 25 a whole number. So a whole number is a number that stands on its own. 26 A number without a little bit more. Ok?

The teacher consistently treats the students' answers as important. All ideas are given a public forum and provide models for others in the class. Also, since the students made decisions about their ideas in a group, they have high epistemic authority. 'We think' (8) suggests that the group has been in discussion and arrived at agreement. It is skilful to give everyone a voice, running the risk of displaying inaccurate models, whilst ultimately pursuing the right answer, in order to display a good example.

\subsection{Topic}

\subsubsection{Initiating topic through open invitations}

Extract 3 also illustrates the use of strategies to initiate topic (bold print). These turns are treated by the children as opportunities to supply their own ideas and understandings. The format is an open invitation, designed as 'What do you think?' in lines 4, 7 and 17. As a mental verb, 'think' orients to the students' thoughts and ideas and use of 'you' is suited to hearing their voices. Furthermore, there is frequent use of modalities such as 'might' $(4,17)$ and 'could' (22). Modalities suggest that a range of responses are possible rather than a single correct answer.

\subsubsection{Open and closed approaches to topical pursuit}

How topic is pursued in order to explore concepts is done in different ways by TAs and teachers. Student-oriented open feedback results in elaborate 
student explanations whereas closed questions have different effects. In (4), the teacher uses questions (lines 1,111 ) but opens up the talk in the $\mathrm{F}$ turn when she asks Jack/Ruka to justify their reasoning. An open topic elicitor, 'Tell me why/how', allows for a range of possible responses. In response, Jim and Ruka explain their earlier, brief answers. Indeed, their explanations, especially when further elaborated, provide useful accounts for others in the class of their working-out strategies. Such open feedback is valuable in the $\mathrm{F}$ turn following the student's answer. Yet, the teacher is privileged because she can select any member of the class to demonstrate their reasoning. By contrast, the TA is working with a single child or small group and therefore can only draw on their resources.

(4) Student-oriented open feedback (Teacher 1)

(10 minutes into whole class discussion.

Sam has Aspergers. Jim, Gina and Ruka have no difficulties.)

$1 \mathrm{~T}$ so a whole number one. Do you think one is a whole number Jim?

2 J Yes (quiet)

$\rightarrow \quad 3 \mathrm{~T}$ You do. Tell me why you think that.

$4 \mathrm{~J}$ Because it doesn't have any

$5 \mathrm{~T}$ Sorry darling? Sam was interrupting us.

$6 \mathrm{~J}$ Because it doesn't have any over.

$7 \mathrm{~T}$ Because it's standing on its own. Yes. It doesn't have a decimal or

8 a fraction or anything. Ok..... ((missing turns))

$111 \mathrm{~T}$ What do you think it could be Gina?

112 G Ten

$113 \mathrm{~T}$ Well done. Is she right Ruka?

$114 \mathrm{R}$ Yes

$\rightarrow 115$ T How do you know? Tell me how you know she's right. So if 116 you're rounding 12 to the nearest 10.

$117 \mathrm{R}$ Because if it's, it's because if it's more than five to nine it goes up $118 \mathrm{~T}$ Ok fine. So, if you're number is between which, if we want to go 
119 back down?

$120 \mathrm{R}$ Uhh It's between one and four.

In the same lesson, the TA uses a closed question with the grammatical format of a yes-no interrogative (extract 5 ). The only option after a yes-no question is agreement or disagreement and, although the student response is unclear, it is brief. Furthermore, 'do you understand' is not positioned in the F turn, but in the middle of the TA's own turn whilst she is explaining the working-out strategy. A risk of placing a check in mid-turn is that the pupil may be minimally engaged and/or inattentive. Alternatively, if the TA had asked to justify reasoning, (as 4), Tom would have been an active participant in the exchange and more fully engaged.

Extract (5) Closed question (TA 1)

(43 minutes into lesson doing independent bookwork. Tom has support for learning)

1 TA So if you've got a 150 here it's going to go upward isn't it.

$\rightarrow 2 \quad$ Because it's five or more. So two hundred. Do you understand?

3 Tom $^{* * * *}$ (unclear)

4 TA Because if you've got a hundred and fifty

5 $\star \star *$

$\rightarrow 6$ Do you understand me darling?

7 Tom ***

$8 \mathrm{~T} \quad$ Back to their desks I think.

In a secondary lesson on geometry, both the teacher and the TA use closed questions but there are different effects. The teacher calls on students' prior knowledge of technical terms and properties ('did you know'; 'do you remember?'). She flags up key concepts for noticing by referring to the 'special name' and contrasts the properties of the 'isosceles' triangle (11) with the better-known right-angled one (29).

(6) Student orientation to explore terms and concepts (Teacher 4) 
(34 minutes into lesson, drawing geometric shapes. The teacher is roving. Matthew has Aspergers.)

$1 \mathrm{~T}$ Ok what's the name of that shape?

2 M Triangle

$\rightarrow 3 \quad T \quad$ It's a triangle. Did you know the special name it has? special

$4 \quad$ name. Let's have a look over here. Look. Ok. Let's see. Thank

5 you. Just have a look over there Matthew, the blue folder over

6 there and see if you can find the names of the

7 M Shape

$8 \mathrm{~T}$ This shape

9 M Shape it's called shape on the board

$\rightarrow 10 \mathrm{~T}$ See if you can find the actual name of it. It's got a special name

$\rightarrow 11$ Those two sides are the same. Good. What measurements are... (Several turns about measurement and shape names)

$\rightarrow \quad 28 \quad \mathrm{~T} \quad$ Elaine what's the special name of this triangle? Do you

$\rightarrow \quad 29$ remember the names of the triangles? We know what a rightangled triangle looks like. Do we know what the name?

$\rightarrow 30 \quad$ Do we know what the special name of this triangle is?

$\rightarrow 32 \mathrm{~T}$ No? A something triangle

$33 \mathrm{C}$ Isosceles triangle

$34 \mathrm{~T}$ Say it again Costa

35 C Isosceles

$36 \mathrm{~T}$ An isosceles triangle. Well done.

The TA is silent throughout most of the lesson (extract 7). Her main involvement, orally, is to support on-task behaviour (1 and 4); she uses three closed questions (2-3) addressing task completion. She refers to conceptual knowledge when asking the boys to write down 'isosceles'. Repetition of technical vocabulary supports the child's learning of the concept. The TA does not explore the students' understanding of the properties of shapes here, or elsewhere, in this lesson. She does not, for example, prompt recall of the name and properties of an isosceles triangle. 
(7) Closed questions and task completion (TA 4)

(31 minutes into same lesson; TA is giving feedback on drawings.

Matthew has Aspergers.)

1 TA When you're working l'll explain.

$\rightarrow 2 \quad$ Matthew are you writing the names down? Have you put

$\rightarrow 3$ isosceles on there? Right. Can you write there isosceles triangle.

$4 \quad$ Ok boys. Right Sian. Sit up, sit up.

\subsection{Repair: Use of feedback, other-initiation and correction}

Given that TAs usually work with pupils who have SEN, it is unsurprising that many of the children's turns are either inaccurate or phrased minimally. How TAs phrase their feedback is crucial, not only owing to the high frequency, but because this turn affords a contingent opportunity for enhancing thinking and fostering independence.

\subsubsection{Quality feedback to enhance understanding}

In (8), the teacher provides very clear feedback (5-8) concerning why Ruka's response is incorrect, and also extends her understanding. She marshals her own conceptual grasp of place value to give the explanation and then refocuses Ruka on the problem by repeating what is needed. The hint about needing 'two zeros' is taken up by the three students who answer in the following turns. When the correct answer is given (13), she takes another opportunity to enhance their understanding by reminding them of how to decide when to 'round up'.

(8) High quality feedback (Teacher 1)

(17 minutes into lesson; whole class discussion.

Tom has support for learning.)

$1 \mathrm{~T}$..if I was rounding to the nearest 100 (.) say if I had 172.

2 What would that be if I rounded to the nearest 100 ? Not to the 


$\begin{array}{rllll} & 3 & & \text { nearest ten, to the nearest 100? Ruka? } \\ & 4 & \mathrm{R} & \text { A hundred and seventy. } \\ \rightarrow & 5 & \mathrm{~T} & \text { That would be to the nearest ten. I want it to the nearest } 100 . \\ \rightarrow & 6 & & \text { Seventy I know you've got 170, but you're still rounding to the } \\ \rightarrow & 7 & & \text { nearest ten. I want it to the nearest } 100 \text { which means I have to } \\ \rightarrow & 8 & & \text { have two zeros. Yes Gianni? }\end{array}$

\subsubsection{TA giving the answer (F as direct correction)}

All of the TAs use different strategies from the teacher. For example, as in (9), instead of initiating repair, the TA uses the $F$ turn to supply the correct answer (3 and 8). Furthermore, the turns are formed to seek agreement since they are either a Y/N question (3) or a final 'Yes?'. The only subsequent response is either 'yes' or 'no', a minimal contribution. The TA did take an opportunity at 5-6 to explain how to work out the answer. This feedback would have been more powerful at line 3 , since it would have prompted him to think of the answer independently. Sam could then have made the final decision which would have increased his epistemic authority.

(9) Giving the answer (TA 1)

(21 minutes into lesson: Discussing how to round 111 to the nearest 10. Sam has Aspergers.)

1 TA So what number are you going to take it to? 
2 Sam Dunno

$\rightarrow 3$ TA Ten isn't it?

4 Sam Yes

5 TA If you've got to take it to the nearest ten, you've got ten or twenty.

$6 \quad$ Eleven is closer to ten isn't it?

7 Sam So is it two hundred then?

ERROR

$\rightarrow 8$ TA So it's a hundred and ten. Yes?

9 Sam Yes

\subsubsection{Withholding the answer through other-initiation (prompts and} hints)

In a year 8 lesson, students are converting a decimal (1.9) into a whole number and a fraction. In (10) and (11) they display a lack of understanding (error at 6). The teacher example shows how she employs a series of moves in the $\mathrm{F}$ turns that enable the student to find the answer independently. First, she gives a clear message that there is an error (7); next, she uses hints (8, $11)$ and prompts $(13,15)$ that foster self-regulation. Overall, she offers a number of strategies that could be used by the pupil to work out the problem alone.

(10) Correction withheld (Teacher 3)

(16 minutes into lesson; doing book exercises. Teacher is roving round. Jaime has support for behaviour.)

$1 \mathrm{~T}$ How many numbers are after the decimal point?

$2 \mathrm{~J}$ One

$3 \mathrm{~T}$ So how many zeros are you going to have?

$4 \mathrm{~J}$ One

$5 \mathrm{~T}$ One. So it's going to be over what.

$6 \mathrm{~J}$ Nine over one ERROR

$\rightarrow 7 \quad \mathrm{~T} \quad$ No what's it going to be.

$\rightarrow 8$ What's the number without the decimal point.

$9 \quad(1.0)$ 
$\rightarrow 10 \mathrm{~T} \quad$ Nineteen over ten, which can be shortened to, without the

$\rightarrow 11$ decimal point, to make it easier? How many tens in nineteen?

$12 \mathrm{~J}$ One.

$\rightarrow 13 \mathrm{~T}$ Remainder?

$14 \mathrm{~J}$ Nine.

$\rightarrow 15 \mathrm{~T} \quad$ Nine. So you have one whole one and nine what?

$16 \mathrm{~J}$ One point nine er (3.0)

$17 \mathrm{~T}$ Nineteen over ten.

$\rightarrow 18$ So you have one whole one and what would you have in there?

19 St Nine?

$\rightarrow 20 \mathrm{~T}$ Over?

21 St Ten

$22 \mathrm{~T}$ One and nine over ten. One whole one and nine over ten. Right...

Our TAs rarely used other-initiation strategies in response to a student error. Instead, in (11), questions are used (1 and 3) that foster independent thinking, but when Liam encounters difficulty (4) the feedback moves are phrased minimally (9). Generally, the F moves either supply the answer or afford a high level of prompting to ensure that the youngster achieves success. Given that the TA works in close proximity to this student on a daily basis, she may well be orienting to the student's difficulties in learning mathematics and therefore making use of strategies to ensure that he achieves success. Yet, over-use of high level prompts can increase dependency on the adult so techniques are needed that maximise students' opportunities to think and work out a solution on their own.

(11) (TA 3)

(20 minutes into lesson; doing book exercises.

Liam has support for literacy.)

1 TA How many times does ten go into nineteen?

2 L One

3 TA One so put a one here (.) right. How many have we got left over?

4 L Eighteen? ERROR 
$\rightarrow 5$ TA No.

6 L Ten?

$\rightarrow 7$ TA No (.) if you've got=

$8 \mathrm{~L}=\mathrm{a}$ hundred

$\rightarrow 9$ TA Take ten from nineteen.

$10 \mathrm{~L}$ Nine.

$\rightarrow 11$ TA Nine (.) so you've got nine tenths. One and nine tenths. Yes, 12 Right. Fiona put the chair down.

\subsubsection{Absence of repair}

Extract 12 supports the findings of the DISS study: the explanations that are used to assist the student are incorrect at both lines 6 and 18-19 and the TA does not self-repair these errors. She may lack conceptual understanding of place value, notably hundreds, tens and units. In saying ' 75 is above 50' and 'thirty four' she is mixing up 'hundreds' with 'tens' and 'units' so Sue risks confusion about the concepts that she is trying to explain and clarify. There are also contradictory instructions; 'round it up' is repeated twice at line 10, giving Sue the message to go up (not down) to the next thousand and, at line 15 , she does supply an answer that is higher. In 16 the TA shows that what she wanted was 'rounding down', not 'up'. The absence of self-repair suggests that contradiction or inaccuracy is not recognised by the TA. Inaccurate information clearly poses challenges for students.

(12) Inaccuracies and contradiction (TA 1)

(29 minutes into lesson; working with small group.

Sue has no learning difficulties.)

1 TA One thousand seven hundred and fifty one. But then it's to go to

2 the nearest thousand. What would I do?

3 Sue Go to the nearest thousand.

4 TA Right. So the nearest thousand is::

5 Sue Two.

$\rightarrow 6$ TA $\quad$ Two. hmm. Good girl. Because seventy five is above fifty.

$7 \quad$ Do you understand? 
8 Sue Yes.

9 TA Promise? Let's give you another one then.

$\rightarrow 10$

Ok round that up to the nearest thousand. Right? Round that up to the nearest thousand. Remember what I said. Two thousand three hundred and forty. That will be what?

13 Sue Two thousand (.) three (.) two thousand three hundred and forty

14 TA Yes. To the nearest thousand is::?

15 Sue Three thousand.

$\rightarrow 16$ TA You didn't round it down did you? If you tell me you understand if you don't I won't be able to help you sweetheart. All right. Now look thirty four. Look let me show you (.) you've got nought to fifty and then you've got fifty to ninety-nine....

\section{DISCUSSION}

Our key finding is that teachers generally 'open up' the students whereas TAs 'close down' the talk. In terms of turn-taking, inclusive teaching is evident when teachers use strategies to ensure the participation of a range of students and convey messages that all contributions are valued. In relation to topic initiation, teachers use open invitations that students interpret as opportunities to offer their ideas. When pursuing topic, teachers employ open feedback strategies to get children to justify their reasoning. They also prompt students to think of technical terms, explain working-out strategies and reinforce the properties of mathematical concepts. In terms of repair strategies, when responding to incorrect answers, teachers withhold outright correction and never supply the correct answer outright. As found in other studies, they use other-initiations of repair by supplying hints and prompts (Radford, 2010a; 2010b). Overall, within each lesson, teachers use at least some strategies that foster student independence and encourage pupils to think for themselves.

By contrast, TAs 'close down' students, both linguistically and cognitively. TAs play a supportive role when listening to the teacher; they keep students ontask and strategies that foster active oral participation are possible. In terms of 
topic generation, TAs have fewer opportunities, owing to their individualised support role, to open up the topic. Closed questions are used to support and encourage students to complete written tasks. This emphasis on task completion might arise from a belief that teachers value completed written work over oral discussion. In terms of pursuit of topic to explore concepts, TAs are well placed to offer such one-to-one support. In relation to repair, when students make errors or fail to find the answer, TAs readily supply it or correct immediately. The absence of scaffolding strategies, such as prompts, hints and withholding answers means that pupils have fewer opportunities to think for themselves. On the other hand, by supplying answers, TAs ensure that learners succeed and avoid the emotional consequences of failure. However, inaccurate explanations and contradictory information as well as unhelpful hinting, owing to limited grasp of mathematical concepts, does need addressing.

This analysis adds further detail to the DISS findings (Rubie-Davies et al, inpress). The notion of opening up versus closing down is consistent with the teacher placing a focus on learning by getting students to reason, encouraging high level thinking and supplying feedback about learning, as contrasted with the TAs' emphasis on task completion. Likewise, DISS found teachers being proactive whereas TAs were reactive because they have little time to prepare and are thus required to work 'in the moment'. This inevitably leads to an emphasis on keeping the student on-task and prioritising outcomes as opposed to fostering improvements in understanding.

Our findings also fit the characteristics of effective teaching to promote conceptual understanding in mathematics (Kyriacou et al., 2008). Teachers go beyond IRF by using open topic invitations and some high quality feedback moves such as asking students to explain their method (Wilson, 2006), especially when they initiate repair. By contrast, TAs use mainly closed questions and evaluative feedback. However, there was little evidence by either teachers or TAs of linguistic devices to extend reasoning (e.g. why, so, if, because) (Mercer \& Sams, 2006) or careful use of questions to scaffold thinking (Myhill, 2006). Using such devices is highly skilled, involving following 
students' ideas as well as sensitive listening to their answers (Coles, 2002; Myhill, 2006; Smith \& Higgins, 2006). Should we expect TAs to achieve such proficiency since this may depend on subject knowledge? Furthermore, no country has yet clarified whether or not TAs should provide instruction (Giangreco and Doyle, 2007; Giangreco et al, 2010). Teachers may have different priorities, for example by expecting the TA to offer emotional and psychological support to the learner rather than instruction. In any case, it is worrying that TA-pupil interactions are so pedagogically limited.

This paper illustrates an analytical framework for the study of classroom discourse which has three principal components: turn-taking, topic and repair. For teaching to be dialogic, turn-taking needs to be carefully managed by adult nomination or by shared routines, as opposed to competitive bidding (Alexander, 2008). Students' opportunities to participate can be increased through 'inclusive turn-taking' strategies. In relation to topic, learning is most effective when it is co-constructed and there is active involvement of the student to shape the direction of the discourse (Skidmore, 2003; Wells \& Arauz, 2006). Both 'student-oriented topic initiations' (to generate ideas) and 'student-oriented topical pursuit' (to follow-up their ideas) are clear demonstrations of how to go beyond IRF. TAs could work with small mixedability groups to benefit from the topical contributions of a range of students and thus build on stronger responses.

Finally, repair entails the fundamental distinction between correction (that reduces the student's epistemic authority), and other-initiated repair that fosters active involvement in meaning negotiation. A variety of 'other initiation strategies' are illustrated, including versions of prompting, hinting and supplying a model, adjusted as a form of graduated assistance (Radford, 2010a; 2010b). Future research needs to identify what forms of other-initiation are suited to increasing and reducing student support on a moment-bymoment basis. How multimodal features such as gaze and gesture accompany verbal elements is also crucial (Radford \& Mahon, 2010). Indeed, TAs could make a valuable contribution in development a classroom culture that encourages risk-taking in terms of making mistakes. 


\subsection{Lessons learnt for management and training}

These strategies do not necessarily represent the talk of all TAs. Given targeted training from specialist teachers or therapists, staff might demonstrate different oral skills. The negative relationship found between TA support and academic progress shows the consequences for academic performance under normal classroom conditions, not targeted interventions where training has been provided. When TAs are prepared and trained for specific curricular interventions, with support and guidance from the teacher and school, there are positive effects on pupil progress (Alborz et al., 2009). Also, when given explicit preparation and scripted lessons they are successful in promoting student learning (Ryder et al, 2008). Yet, most studies have targeted literacy skills whereas numeracy studies are rare. Our findings contribute to the need for rigorous evidence-based practice.

In terms of management issues, how TAs are recruited is of the utmost importance. If they are to have a pedagogical role, it is essential that there is a good conceptual grasp of subject knowledge, which is reflected in their qualifications. Another issue for school leaders is the need for regular prelesson planning and preparation time for teachers and TAs (Blatchford et al, 2009a).

Next, there are urgent implications for the training and preparation of TAs. Understanding of core curricular content is paramount. Blatchford et al, (2009a) found that TAs often felt under prepared for their roles and many picked up subject and pedagogical knowledge by 'tuning in' to the teachers' delivery. As the role is primarily oral, TAs would also benefit from training in the principles and purpose of dialogic discourse (Alexander, 2008; Fisher, 2007). They require modelling of discourse techniques, including open invitations and how to use quality feedback turns (Radford, 2006; 2010a; 2010b).

Finally, teachers own preparation does not build on the reality that TAs are working in an instructional capacity. The DISS project found that three 
quarters of teachers reported never having any training or development to help them work with TAs or other support staff, even though the numbers of teachers involved in training support staff had increased markedly (Blatchford et al, 2009c). Teachers therefore now have a management role which demands skills in people management, but for which they are typically not trained (Rubie-Davies et al., in press). Our data suggest a number of areas to cover via pre-service and within-school training (planning, expectations, lesson preparation, modelling language and explanations). Teachers should also expect to regularly monitor their TAs, in-class, in terms of the quality of discourse and the accuracy of their explanations.

TA-pupil interactions represent the finest point at which the effects of decisions made by school leaders and teachers are brought to bear. The features of TA-pupil talk are symptomatic of factors concerning TAs' employment, deployment, training and preparation, which operate at the school and classroom level. The effect of these factors at the sharp end (e.g. TA-pupil interaction) is that TAs require extensive training, preparation and support to facilitate pupil talk and thinking. We must be cautious therefore when interpreting the effect of interactions alone on pupil learning. The DISS project offers a framework - the Wider Pedagogical Role model - for interpreting the effects of interactions and the wider effects of TA deployment and preparation (e.g. training and pre-lesson communication). The WPR model takes account of the situational and structural factors within which TAs work, and which maximises or inhibits their effectiveness (see Blatchford et al, 2009a; Webster et al, in prep).

Yet by starting at the finest point and working outwards, we can see an immediate and relatively straightforward way in which teachers can help to improve TAs' practice: by sharing their own higher order skills and knowledge and helping TAs to develop questioning techniques that open up interactions with pupils and to know how to provide quality feedback.

Data from the DISS project has afforded the first opportunity to record and analyse TA-pupil interactions and compare them with teacher-pupil 
interactions, as they occur under everyday conditions in mainstream classrooms. Given the importance of the findings for teacher and TA training and development, an important area for future research would be the development and evaluation of effective strategies to improve TAs' interactions with pupils in mathematics and other curriculum areas. The analytical model of turn-taking, topic and repair will prove invaluable for designing training programmes and for evaluating changes in interactional behaviour.

In terms of future research, we could add to understanding of direct learning support, by studying types of talk that can boost 'soft' skills that indirectly support learning; e.g. motivation, confidence, independence, etc. Given the problematic nature of the direct pedagogical role of TAs, it would be helpful to have more information on ways in which the role might be less heavily instructional and instead reflect a 'secondary' rather than the 'primary' educator role found in the DISS project. This particularly applies to pupils with SEN/disabilities who spend much more time receiving instruction from TAs than their peers. With these pupils in mind, further areas of research might include more specialist training for teachers and TAs in interacting with pupils with particular types of SEN (e.g. Aspergers), thus reflecting more nuanced approaches to interactions with pupils.

\section{Acknowledgement}

We thank Maria Koutsoubou for her valuable work on data collection. We would also like to thank the staff and students of the participating schools for their cooperation and patience. The research was funded by the DCSF and the Welsh Assembly Government. The views expressed in this paper are the authors and do not necessarily reflect those of the funders. 


\section{References}

Alborz, A., Pearson, D., Farrell, P., \& Howes, A. (2009). The impact of adult support staff on pupils and mainstream schools, DCSF/London, IoE, Evidence for Policy and Practice Information and Co-ordinating Centre (EPPI Centre).

Alexander, R. (2001). Culture and pedagogy: international comparisons in primary education. Oxford, UK: Blackwell.

Alexander, R. (2008). Towards dialogic teaching: rethinking classroom talk. ( $4^{\text {th }}$ ed.). Dialogos, UK: University of Cambridge.

Berliner, D. (1987). Simple views of effective teaching and a simple theory of classroom instruction. In D. Berliner \& B. Rosenshine (Eds.), Talks to teachers (pp. 93-110). New York: Random House.

Berliner, D. (1994). Describing the behaviour and documenting the accomplishments of expert teachers. Bulletin of Science, Technology and Society, 24, 200-212.

Blatchford, P., Bassett, P., Brown, P., Koutsoubou, M., Martin., C., Russell, A., \& Webster, R. with Rubie-Davies, C. (2009a). The impact of support staff in schools. Results from the deployment and impact of support staff project (Strand 2, Wave 2). DCSF-RR148. London: Department for Children, Schools and Families.

Blatchford,, P., Bassett, P., Brown, P. \& Webster, R. (2009b). The effect of support staff on pupil engagement and individual attention. British Educational Research Journal, 35, 661-686.

Blatchford,P., Bassett, P., Brown, P., Martin, C., Russell, A. \& Webster, R. (2009c).The deployment and impact of support staff in schools: Characteristics, working conditions, job satisfaction and impact of workforce remodelling. Report on findings from the three national questionnaire surveys of schools, support staff and teachers. (Strand 1 Waves 1-3 - 2004, 2006 and 2008) (DCSF-RR154). London:

Department for Children, Schools and Families.

Blatchford,, P., Bassett, P., Brown, P., Martin, C., Russell, A. \& Webster, R. (in pressa) The impact of support staff on pupils' 'positive approaches to learning' and their academic progress. British Educational Research Journal. (published as IFirst Article). 
Bourke, P. \& Carrington, S. (2007). Inclusive education reform: implications for teacher aides. Australasian Journal of Special Education, 31, 1524. http://eprints.qut.edu.au/5388/1/5388_1.pdf

Cazden, C. (2001). Classroom discourse: the language of teaching and learning. ( $2^{\text {nd }}$. ed.). Portsmouth, Heinemann.

Coles, A. (2002). Teaching strategies related to listening and hearing in two secondary classrooms. In J. Winter \& S. Pope (Eds.), Research in Mathematics Education, Vol 4. (pp.21-34). London: British Society for Research into Learning Mathematics.

DCSF (2009). Your child, your schools, our future: building a $21^{\text {st }}$ century schools system. London: The Stationery Office.

DfES (2002). Time for standards: Reforming the school workforce. London: DfES.

Fisher, R. (2007). Dialogic teaching: developing thinking and metacognition through philosophical discussion. Early Child Development and Care, 177, 615-631.

Giangreco, M., Suter, J. \& Doyle, M. (2010). Paraprofessionals in inclusive schools: A review of recent research. Journal of Educational and Psychological Consultation, 20, 41-57.

Giangreco, M. \& Doyle, M. (2007). Teacher assistants in inclusive schools. In L. Florian (Ed.), The Sage handbook of special education. London: Sage.

Gibson, W. (2009). Negotiating textual talk: conversation analysis, pedagogy and the organisation of asynchronous discourse, British Educational Research Journal, 35, 705-721.

Hardman, F., Smith, F., \& Wall, K. (2005). Teacher-pupil dialogue with pupils with special educational needs in the national literacy strategy. Educational Review, 57, 299-316.

Hauser, E. (2005). Coding 'corrective recasts': the maintenance of meaning and more fundamental problems, Applied Linguistics, 26, 293-316.

Have, P. ten (2007). Doing conversation analysis: A practical guide. ( $2^{\text {nd }}$ ed.). London: Sage.

Jones, R. \& Thornborrow, J. (2004). Floors, talk and the organisation of classroom activities, Language in Society, 33, 399-423. 
Koshik, I. (2002). Designedly incomplete utterances: a pedagogical practice for eliciting knowledge displays in error correction sequences, Research on Language and Social Interaction, 35, 277-309.

Kyriacou, C., \& Issitt, J. (2008). What characterises effective teacher-initiated teacher-pupil dialogue to promote conceptual understanding in mathematics lessons in England in Key Stages 2 and 3: a systematic review. Report: In Research Evidence in Education Library. London: EPPI-Centre, Social Science Research Unit, Institute of Education, University of London.

Logan, A. (2006). The role of the special needs assistant supporting pupils with special educational needs in mainstream primary schools. Support for Learning, 21, 92-99.

Macbeth, D. (2006). The relevance of repair for classroom correction, Language in Society, 33, 703-736.

McHoul, A. (1990). The organisation of repair in classroom talk, Language in Society, 19, 349-377.

Mercer, N. \& Sams, C. (2006). Teaching children how to use language to solve maths problems. Language and Education, 20, 507-528.

Myhill, D. (2006). Talk talk talk: teaching and learning in whole class discourse. Research Papers in Education, 21, 19-41.

Radford, J. (2009). Word searches: on the use of verbal and non-verbal resources during classroom talk. Clinical Linguistics and Phonetics. 23, 1-13.

Radford, J. (2010a). Practices of other-initiated repair and correction in SSLD classroom discourse. Applied Linguistics, 31, 25-44.

Radford, J. (2010b). Adult participation in children's word searches: on the use of prompting, hinting and candidate offers. Clinical Linguistics and Phonetics. 24, 83-100.

Radford, J., Ireson, J., \& Mahon, M. (2006). Triadic dialogue in oral communication tasks: what are the implications for language learning? Language and Education, 20, 191-210.

Radford, J. \& Mahon, M. (2010). Multimodal participation in storybook 
sharing. In: H. Gardner \& M. Forrester (Eds.), Analysing interactions in childhood: Insights from conversation analysis. (pp 209-227).

Chichester: John Wiley \& Sons.

Radford, J. \& Tarplee, C. (2000). The management of conversational topic by a ten-year-old child with pragmatic difficulties, Clinical Linguistics and Phonetics, 14, 387-403.

Ridley, J., Radford, J., \& Mahon, M. (2002). How do teachers manage topic and repair? Child Language Teaching and Therapy, 18, 43-58.

Rubie-Davies, C., Blatchford, P., Webster, R., Koutsoubou, M. \& Bassett, P. (in press). Enhancing student learning? A comparison of teaching and teaching assistant interaction with pupils. School Effectiveness and School Improvement.

Ryder, J., Tunmer, W., \& Greaney, K. (2008). Explicit instruction in phonemic awareness and phonemically based decoding skills as an intervention strategy for struggling readers in whole language classrooms. Reading and Writing, 21, 349-369.

Sacks, H., Schegloff, E. \& Jefferson, G. (1978). A simplest systematics for the organisation of turn-taking for conversation. In: J. Schenkein (Ed.), Studies in the organisation of conversational interaction (pp.755). New York: Academic Press.

Schegloff, E. (2007). Sequence organisation in interaction: a primer in conversation analysis. Cambridge: Cambridge University Press.

Schegloff, E., Jefferson, G., \& Sacks, H. (1977). The preference for selfcorrection in the organization of repair in conversation. Language, 53 , 361-382.

Silverman, D. (2006). Interpreting qualitative data: methods for analysing talk, text and interaction. London: Sage.

Skidmore, D., Perez-Parent, M. \& Arnfield, S. (2003). Teacher-pupil dialogue in the guided reading session. Reading, 37, 47-53.

Smith, F., Hardman, F., Wall, K., \& Mroz, M. (2004). Interactive whole class teaching in the national literacy and numeracy strategies. British Educational Research Journal, 30, 395-411.

Smith, H. \& Higgins, S. (2006). Opening classroom interaction: the 
importance of feedback. Cambridge Journal of Education, 36, 485502.

Webster, R., Blatchford, P., Bassett, P., Brown, P., Martin, C., \& Russell, A. (2010). Double standards and first principles: framing paraprofessional support for pupils with special educational needs. European Journal of Special Needs Education, 25, 319-336.

Webster, R., Blatchford, P., \& Russell, A. (in preparation). The wider pedagogical role of teaching assistants.

Wells, G. (1993). Re-evaluating the IRF sequence: a proposal for the articulation of theories of activity and discourse for the analysis of teaching and learning in the classroom, Linguistics and Education, 5, 137.

Wells, G. \& Arauz, R. Dialogue in the classroom. Journal of the Learning Sciences, 15, 379-428.

Wilson, L., Andrew, C., \& Below, J. (2006). A comparison of teacher-pupil interaction within mathematics lessons in St. Petersburg, Russia and the north-east of England. British Educational Research Journal, 32, 411-441. 
Table 1: Schools

\begin{tabular}{|c|c|c|l|l|l|}
\hline School & $\begin{array}{c}\text { Number } \\
\text { pupils }\end{array}$ & $\begin{array}{c}\% \\
\text { FSM }^{*}\end{array}$ & $\begin{array}{c}\text { Geographical } \\
\text { area }\end{array}$ & \multicolumn{1}{|c|}{ SEN information } & $\begin{array}{c}\text { Year group } \\
\text { observed }\end{array}$ \\
\hline 1 & 475 & 40 & E. London & 12 statements & 5 (9-10 yrs $)$ \\
\hline 2 & 90 & 7 & S. Wales & $\begin{array}{l}17 \% \text { on SEN } \\
\text { register }\end{array}$ & $5 / 6^{\star *}(9-11 \mathrm{yrs})$ \\
\hline 3 & 806 & - & S. England & 'low number' & $8(12-13 \mathrm{yrs})$ \\
\hline 4 & 869 & $\star \star \star$ & S. E. England & 'above average' & $8(12-13 \mathrm{yrs})$ \\
\hline
\end{tabular}

${ }^{*}$ FSM: free school meals as an index of low income.

${ }^{* *}$ Class was a mixed year 5 and 6 .

*** "The number of students who take up free school meals is average although many more are eligible" (Ofsted). 
Table 2: Lesson focus and role of TA

\begin{tabular}{|c|c|c|}
\hline School & Role of TA & Mathematical focus of lesson \\
\hline TA 1 & $\begin{array}{l}\text { Support two children } \\
\text { with statements* }\end{array}$ & $\begin{array}{l}\text { Difference between fractions and whole numbers. } \\
\text { Rounding up/down to the nearest } 10,100,1,000 \text {. }\end{array}$ \\
\hline TA 2 & $\begin{array}{l}\text { Support child with } \\
\text { SEN in small group }\end{array}$ & Long division with remainders. \\
\hline TA 3 & $\begin{array}{l}\text { General SEN } \\
\text { support** }\end{array}$ & $\begin{array}{l}\text { Converting decimals to whole numbers and } \\
\text { fractions. }\end{array}$ \\
\hline TA 4 & $\begin{array}{l}\text { Support boy with } \\
\text { statement }^{* * *}\end{array}$ & $\begin{array}{l}\text { Geometry: properties of triangles and making } \\
\text { box-like nets. }\end{array}$ \\
\hline
\end{tabular}

* One boy with Aspergers, an autistic spectrum disorder (Sam) and one who has additional support for learning (Tom)

** A mixed group: Liam has a literacy difficulty, Fiona has a statement for Attention Deficit Hyperactivity Disorder, Jaime has additional support for behaviour.

${ }^{* * *}$ A boy with Aspergers (Matthew)

A 'statement of SEN' in the UK spectifies significant additional resources, often supplied by a TA. 